\title{
Arqueologia da Paisagem pelo viés geossistêmico: Sítio Arqueológico Piracanjuba, Munícipio de Piraju-SP
}

\section{Landscape Archeology from a geosystemic perspective: the Piracanjuba archaeological site, municipality of Piraju, state of São Paulo, Brazil}

\section{Larissa Figueiredo Daves \\ Neide Barrocá Faccio ${ }^{2}$}

\begin{abstract}
Palavras-chave:
Arqueologia da Paisagem

Geossitema

Rio Paranapanema
\end{abstract}

\begin{abstract}
Resumo
Pesquisas referentes à relação da sociedade com o ambiente em tempos pretéritos mostram a relevância de estudos interdisciplinares entre a Geografia e a Arqueologia. Nesse sentido, realizou-se um estudo do Sítio Arqueológico Piracanjuba - um sítio lítocerâmico Guarani, localizado no Município de Piraju, SP, na região do Médio Rio Paranapanema, pelo viés teórico da Arqueologia da Paisagem. No perímetro do sítio arqueológico estudado, evidenciaram-se quatro núcleos de solo antropogênico (NSA), também denominados 'manchas pretas'. Como resultado, o trabalho permitiu analisar o ambiente segundo os pressupostos geossistêmicos horizontais (geofácies e geótopo) e verticais (geohorizontes), a fim de abordar a representação e espacialização cartográfica do sítio em sua relação com as características do complexo físico-geográfico da área. Contribui-se, assim, para estudos a respeito da análise da paisagem de sítios arqueológicos em relação ao tempo pretérito com base em geoindicadores. As unidades de estratificação heterogênea evidenciaram a distinção de cada ambiente, perceptível pela altura de cada estrato de vegetação, além da sinuosidade e declividade da vertente em direção ao corpo d'água do Rio Paranapanema. A análise dos núcleos de solo antropogênico revelou a disparidade da datação por termoluminescência de fragmentos cerâmicos presentes no NSA1 de 1520 d.C. e no NSA 2 de 1355 d.C., apontando, provavelmente, para dois períodos de ocupação da área do sítio arqueológico.
\end{abstract}

\begin{abstract}
Studies on the relationship between society and the environment in past time frames have shown the relevance of interdisciplinary research between Geography and Archeology. Based on the theoretical grounds of Landscape Archeology, this study investigates the Piracanjuba archaeological site, a Guarani lithoceramic site, located by the middle course of the Paranapanema River, in the municipality of Piraju, state of São Paulo, Brazil. Within the perimeter of the archaeological site under study, four anthropogenic soil patches (ASPs), also known as indigenous black earth, were identified. In terms of results, the study produced an analysis of the environment according to the horizontal (geofacies and geotopes) and vertical (geohorizons) geosystemic concepts, examining the site's cartographic representation and spatialization as to its relationship with relevant characteristics of the physical-geographic complex of the studied area. This therefore contributes to further landscape
\end{abstract}

1 Universidade de São Paulo - USP, PPG em Geografia Humana, São Paulo, SP, Brasil. larissadaves@usp.br

2 Universidade Estadual Paulista - FCT/UNESP, Departamento de Planejamento, Urbanismo e Ambiente, Presidente

Prudente, SP, Brasil.nfaccio@terra.com.br 
analyses of archaeological sites, based on geoindicators, within past time frames. The heterogeneous stratification units evinced the distinguishing features of the studied environments according to the height of each vegetation stratum and their slope sinuosity and steepness towards the water body of the Paranapanema River. The analyses of the anthropogenic soil patches revealed, by means of thermoluminescence, disparity in the dating of the ceramic fragments found in ASP 1 reaching back to $1520 \mathrm{AD}$, and in the ASP 2 to 1355 $\mathrm{AD}$, probably pointing to two periods of occupation of the archaeological site area.

\section{INTRODUÇÃO}

Neste trabalho, temos como enfoque a análise da paisagem do Sítio Arqueológico Piracanjuba, localizado, no Município de Piraju, SP, na área do médio Curso do Rio Paranapanema, lado paulista (Figura 1).

O Sítio Arqueológico Piracanjuba está situado em média vertente próximo ao curso do
Rio Paranapanema. Trata-se de um sítio lítocerâmico Guarani. No perímetro deste assentamento guarani foi evidenciado quatro núcleos de solo antropogênico (NSA), também denominado como manchas pretas. Nos NSAs foram encontrados vestígios de combustão pouco estruturados, ao redor dos quais concentrou-se a maior parte da cerâmica encontrada na área do sítio.

Figura 1 - Localização do Sítio Arqueológico Piracanjuba. Município de Piraju-SP.

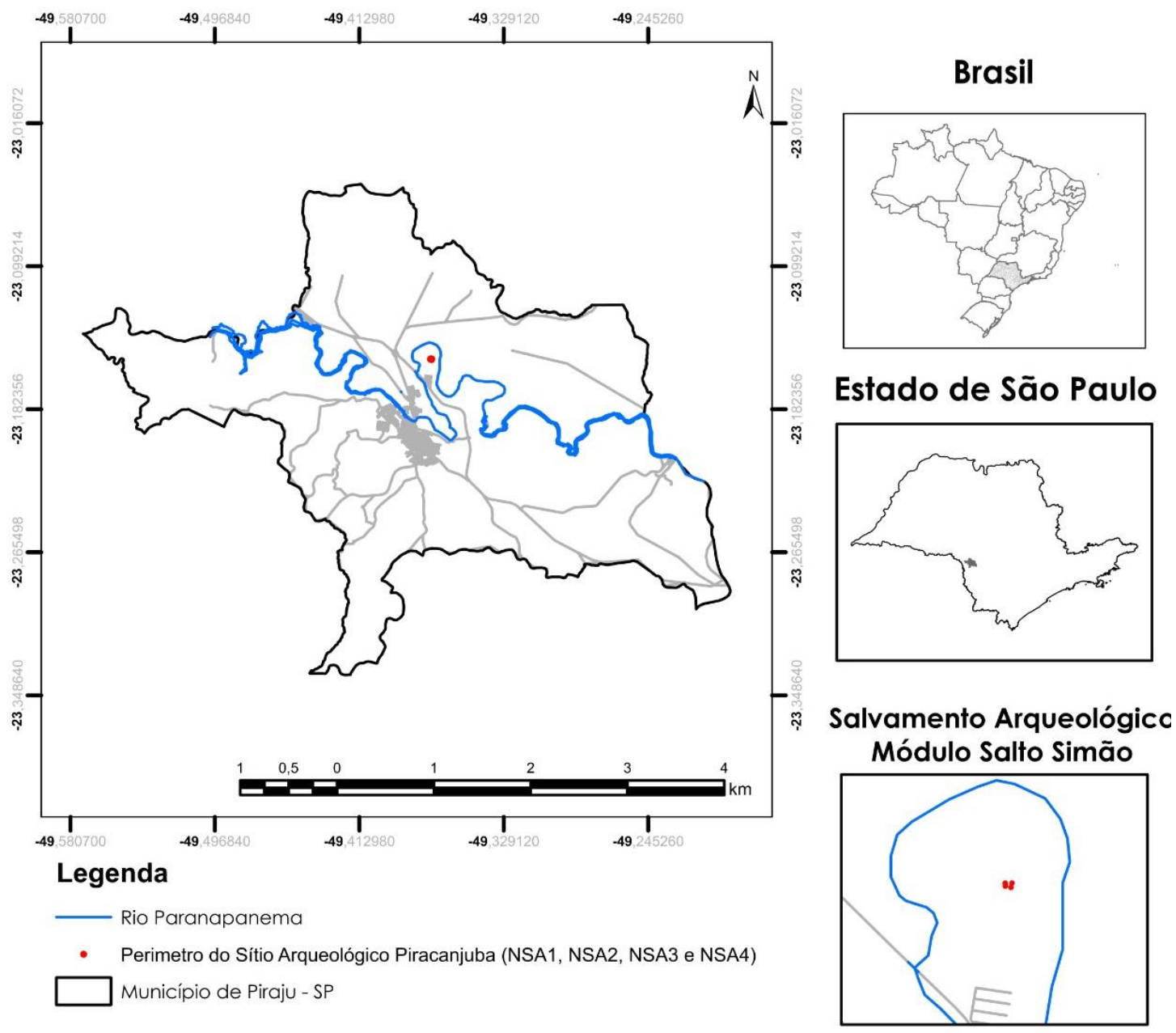

Fonte: Daves (2018). 
Os componentes da paisagem próximos ao perímetro do sítio arqueológico são relevantes para identificar os assentamentos Guarani seja pelo tamanho da aldeia, a localização dos vestígios arqueológicos e as fontes de obtenção de recursos naturais para sua subsistência. As características fisico-geográficas do Rio Paranapanema, principalmente a morfologia e a litologia, condicionaram a forma de apropriação do espaço geográfico por esses grupos indígenas.

A pesquisa arqueológica pode contribuir para a compreensão da formação do espaço e suas transformações pretéritas a partir da ação humana. A abordagem interdisciplinar entre a Geografia e a Arqueologia, sobretudo em sua relação com a paisagem, é investigada, neste trabalho, a partir do viés teórico da Arqueologia da Paisagem. Em virtude disso, tal estudo faz uma reflexão sobre o ambiente que os grupos indígenas habitaram no passado.

Partindo desse pressuposto, neste trabalho temos objetivo de analisar a paisagem do Sítio Arqueológico Piracanjuba com base na Teoria do Geossistema e da Arqueologia da Paisagem, a partir da relacionação existente entre os aspectos físico geográficos da área e a distribuição dos vestígios arqueológicos, a fim de conhecer as características desse assentamento Guarani. Em virtude disso, tal estudo faz uma reflexão sobre o ambiente que o grupo Guarani habitava no passado.

Nessa perspectiva, o Geossistema permitiu a análise do ambiente, seguindo dos pressupostos horizontais e verticais de sua análise, a fim de abordar a representação e espacialização cartográfica da área do sítio, que constitui-se em análise da paisagem. Permite-se assim, entender a distribuição espacial dos fenômenos estudados, tanto em sua estratificação vertical quando em sua estrutura horizontal.

\section{MATERIAIS E MÉTODOS}

Paisagem: conceito interdisciplinar da Geografia e da Arqueologia

A Geografia, desde a sua institucionalização como ciência, busca, enquanto eixo epistemológico central, a relação entre sociedade e natureza (SUERTEGARAY, 2009; CASSETI, 2009). Nesse âmbito, a paisagem tem se mostrado uma categoria essencial ao debate relacional dessas duas categorias (PASSOS, 2003; 2006).

Nesse cenário, o Geossistema permite um olhar sobre a existência dos sistemas e sua funcionalidade em relação ao espaço geográfico, principalmente por meio de uma visão integradora e polissêmica (PASSOS, 2006). Por outro lado, a Arqueologia da Paisagem é o estudo das intervenções humanas construtoras da paisagem, tendo como base os vestígios arqueológicos deixados por essas interações com o meio (BOADO, 1999).

A Arqueologia estuda a paisagem préhistórica, a fim de evidenciar como era a subsistência de determinado grupo humano com base na cultura material, dentro de contextos socioculturais

documentados arqueologicamente. Assim, investiga a organização do espaço e como se deu a experiência humana em determinada área para discutir o contexto histórico, social ou cultural (ASHMORE; KNAPP, 1999).

Para suprir suas novas necessidades de análise, a Arqueologia utilizou métodos com base no conceito de paisagem, de modo que seu instrumento de estudo teve como apoio o campo das ciências naturais. De acordo com Bertrand e Bertrand (2009), a "Arqueologia da Paisagem deve ser apreendida como uma tentativa de reencontrar o vestígio das relações históricas estabelecidas entre a sociedade e a natureza" (BERTRAND; BERTRAND, 2009, p. 171).

Entretanto, os geógrafos e arqueólogos contemporâneos aproximam-se especialmente, quando consideram as paisagens como construtos materiais, pois trazem informação sobre a estrutura e a organização de ocupações passadas, contribuindo como um tipo de texto histórico (KORMIKIARI, 2000). Desse modo, cada ciência fornece um componente essencial para o estudo dos sistemas ambientais, sendo fundamental a interdisciplinaridade em pesquisas arqueológicas (WATERS, 1992).

Bertrand e Bertrand (2009) abordam que o pesquisador, ao utilizar a Arqueologia da Paisagem como método de análise, deve ter como ponto de referência o Geossistema, para reconstituir a existência dos sistemas e sua funcionalidade em relação ao espaço geográfico. Os autores afirmam que a "Arqueologia da Paisagem" deve ser uma pesquisa espacial que não se contenta apenas com a leitura dos limites geométricos, mas que deve analisar as unidades de produção (BERTRAND; BERTRAND, 2009, p. 176).

Seguindo com o mesmo objetivo, temos a Arqueologia da Paisagem, definida como o estudo das intervenções humanas construtoras da paisagem, tendo como base os vestígios arqueológicos deixados por essas intervenções humanas, em tempos pretéritos (BERTRAND, 2009).

A Arqueologia da Paisagem ao ser utilizada como estratégia de pesquisa que inclui o estudo 
de todos os processos sociais e históricos em sua dimensão espacial ou, melhor, que pretende interpretar as paisagens arqueológicas e dos objetos que os especificam. Deve-se pensar sobre o registro da cultura arqueológica e material de uma matriz espacial e, simultaneamente, converter ao espaço em objeto da investigação arqueológica (VICENT 1991; BOADO, 1993).

\section{Escalas de análise vertical e horizontal do Sítio Arqueológico Piracanjuba}

O estudo do Sítio Arqueológico Piracanjuba é apresentado sob viés da paisagem, a partir dos pressupostos análise do ambiente e dos pressupostos geossistêmicos horizontais (Geofácies e Geótopo) (BERTRAND, 1968) e verticais (Geohorizontes) (BEROUTCHACHVILLI; BERTRAND, 1978).

Bertrand (1972) propôs a escala de análise da paisagem, a partir de sua tipologia dinâmica presente na hierarquia dos elementos classificados como unidades superiores (Zona, Domínio e Região natural) e unidades inferiores (Geossistema, Geofáceis e Geótopo). De acordo com o autor o Geossistema é tão somente um modelo e, portanto, uma abstração, diante disso, passou-se a definir as unidades de terreno, de forma hierárquica: Geótopo, Geofácies e Geocomplexos (PASSOS, 2006).

$\mathrm{O}$ estudo teve em vista identificar o complexo geossistêmico no nível de geofácie, geótopo e de geohorizonte. Utilizamos como procedimento estereoscopia analógica sob fotos aéreas da empresa BASE- Aerofotogrametria, do voo s realizado no ano de 1972, na escala de 1:25.000, com vistas a comparar e analisar diferentes aspectos geomorfológicos, ao longo do tempo, no local em que está localizado o sítio arqueológico. A respeito da sistematização dos dados, foram utilizados programas de Sistema de Informação Geográfica (SIG) como ArcGIS e QGis, além do programa de desenho assistido por computador AutoCad e CorelDraw 7.

\section{RESULTADOS E DISCUSSÃO}

\section{O Geocomplexo do Sítio Arqueológico Piracanjuba}

O Sítio Arqueológico Piracanjuba está inserido no Geocomplexo do Módulo Salto Simão, trecho do curso do Rio Paranapanema, onde ocorreu o salvamento arqueológico nos anos 2000 a 2003. Desse modo, Geocomplexo é visto como sistema natural seja pelo seu complexo ambiental o qual está relacionado às características físicas da área e sua transformação ao longo dos anos.

A quarta unidade territorial de análise exposta por Bertrand (1968) denominada geossistema sofre modificação em Beroutchachvilli e Bertrand (1978), sendo assim denominada como geocomplexo, por entenderem o geossistema enquanto uma teoria e não apenas uma escala territorial com dimensão prédefinida. Assim, temos como quadro síntese do contexto ambiental do Sítio Arqueológico Piracanjuba os seguintes níveis de escala da paisagem de acordo com Bertrand (1968) (Quadro 1 e Figura 2). Neste trabalho, o enfoque é dado às unidades da paisagem Geofáceis, Geótopo e Geohorizonte. As unidades zona, domínio e região natural, foram utilizadas apenas para classificação ao nível de escala segundo Bertrand (1968). Com base no contexto ambiental do Sítio Arqueológico Piracanjuba apresenta-se aqui o complexo geossistêmico para o nível de Geofácie, Geótopo e Geohorizonte. No contexto de Geofácie, a análise buscou delimitar o perímetro do sítio arqueológico (localização e padrão de assentamento Guarani). O Geótopo é utilizado para comparar e diferenciar cada solo antropogênico a partir da concentração de material arqueológico (cerâmica, lítico lascado, lítico polido e vestígios faunísticos). $\mathrm{O}$ Geohorizonte abrange o relevo, a cobertura vegetal e a hidrologia na estrutura vertical do sítio arqueológico. 
Quadro 1 - Paisagem do Sítio Arqueológico Piracanjuba segundo os níveis de escala propostos por Bertrand (1968) e Beroutchachvilli; Bertrand (1978).

\begin{tabular}{cl} 
ZONA & $\begin{array}{l}\text { Área Transicional (MONTEIRO, 1973) das massas de ar polares e } \\
\text { tropicais. Critério Climático. }\end{array}$ \\
\hline DOMÍNIO & $\begin{array}{l}\text { Bacia do Rio Paranapanema. Área do Médio Paranapanema. } \\
\text { Critério geológico considerando características texturais, os } \\
\text { ambientes deposicionais e fontes de material (Geoindicadores) }\end{array}$ \\
$\begin{array}{c}\text { REGIÃO } \\
\text { NATURAL }\end{array}$ & $\begin{array}{c}\text { Província das Cuestas Basálticas. Formação Serra Geral. } \\
\text { GEOCOMPLEXO }\end{array}$ \\
Sítio Arqueológico Piracanjuba. Módulo Salto Simão. Piraju, SP \\
GEOFÁCIES & Delimitação do padrão de assentamento do sítio arqueológico \\
GEÓTOPO & $\begin{array}{l}\text { Núcleos de solo antropogênico (NSA 1, NSA 2, NSA 3 e NSA 4) } \\
\text { Posição do Sítio Piracanjuba no relevo (alta, média e baixa vertente) } \\
\text { e seus estratos de vegetação }\end{array}$ \\
\hline
\end{tabular}

Fonte: as autoras

O aspecto geomorfológico da região, onde está inserido o Sítio Arqueológico Piracanjuba apresenta relevo colinoso, fundos de vales com predomínio de vertentes côncavas e convexas, próximas ao Rio Paranapanema e recursos naturais como rochas basálticas, arenitos silicificados e fontes de argila.

Durante o salvamento arqueológico na área do Salto Simão, referente à UHE Piraju no ano 2000, foram evidenciados vinte e seis sítios arqueológicos, mostrando a evidência de habitação de grupos caçadores-coletores e de grupo ceramista Guarani nessa região, em tempos pretéritos (MORAIS; FACCIO; PIEDADE, 2000).

O curso d'água do Rio Paranapanema, antes da construção da UHE Piraju, apresentava-se menor em relação à sua profundidade e largura comparadas ao contexto atual. Os sítios arqueológicos, após a construção da barragem, estão submersos e outra modificação diz respeito ao ambiente fluvial e à cobertura vegetal próxima ao curso d'água, com novas áreas de preservação permanente, seguindo o novo desenho de suas margens.

Destacamos que o grupo que habitou a área do Sítio Arqueológico Piracanjuba, provavelmente, utilizou-se dos barreiros como fontes para obtenção da argila para a confeç̧ão das vasilhas cerâmicas, além do uso de afloramentos rochosos para produção de artefatos líticos.

O local apresenta em seu potencial arqueológico o favorecimento da instalação desses grupos indígenas em tempos pretéritos. O ambiente antes ter seu sistema biótico alterado, apresentava-se, aproximadamente a 300 metros de distância do sítio arqueológico. Essas são condições valorizadas por grupos indígenas Guarani (MORAIS, 1986).

A situação desses sítios arqueológicos está diretamente subordinada ao ambiente do Rio Paranapanema, caso dos sítios localizados nos fundos de vale com depósitos quaternários areno-argilosos na baixa vertente em tempos pretéritos são Tucum, Monjoleiro, Bucuvá, Benjoeiro, Tambuí, Salsa, Pintado, Lambari, Pirambeba, Surubim, Bagre e Ingá.

Entre esses sítios arqueológicos, localizados na porção de baixa concavidade das encostas com contexto ambiental alterado e submerso por conta da implantação da barragem, estão os Sítios Bucuvá, Benjoeiro, Salsa, Tambiú, Pintado, Lambari, Canelinha, Joá-Bravo, Ingá, Bagre e Engenho do Salto. 
Figura 2 - O Geocomplexo do Sítio Arqueológico Piracanjuba, Piraju, SP
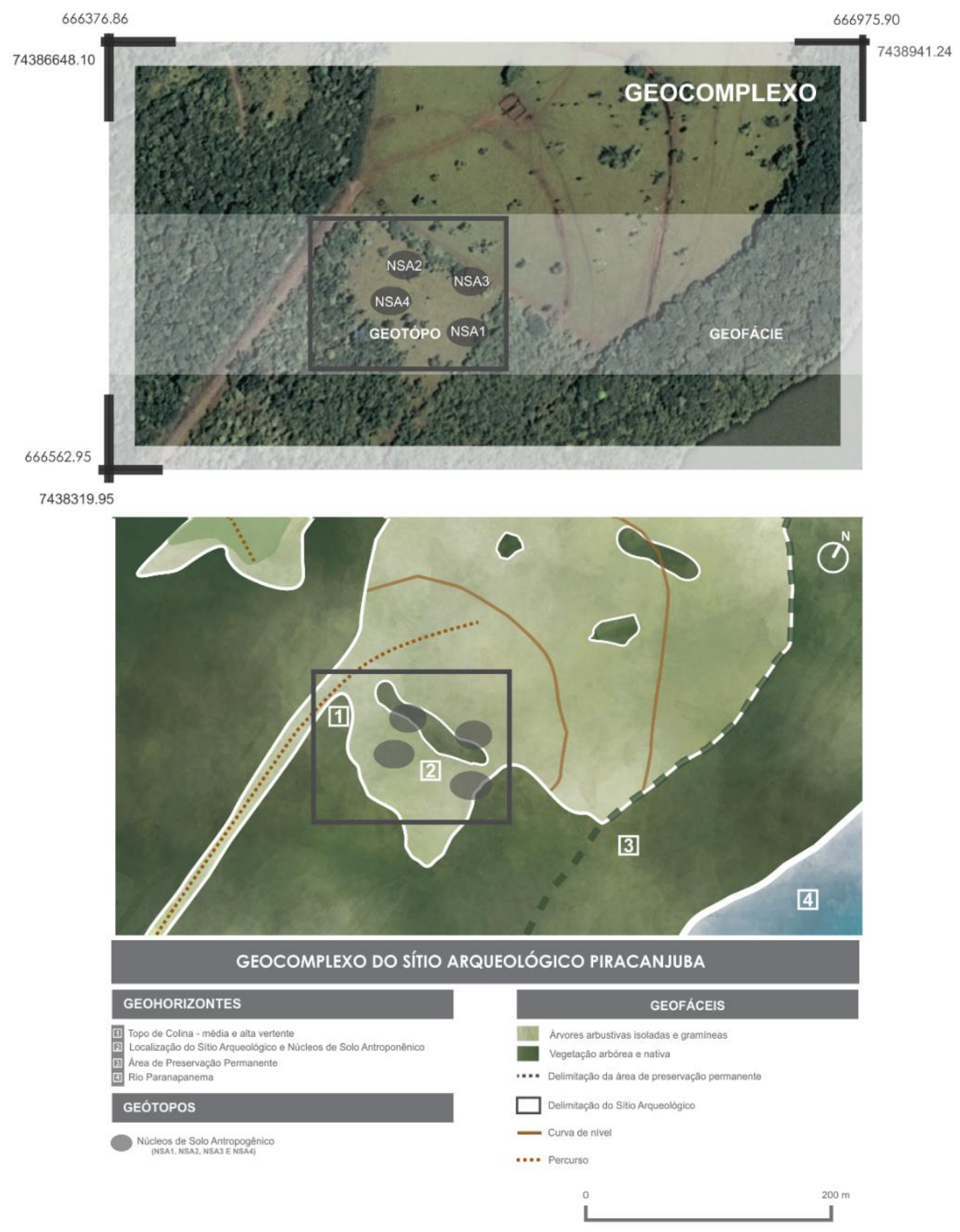

Fonte: Daves (2018).

Na Figura 3, podem ser observados os sítios arqueológicos evidenciados neste salvamento arqueológico e sua área ao entorno do curso do Rio Paranapanema com a presença de geoindicadores, tais como cascalheiras, diques basálticos, arenito intrapiano e fontes de argila no ambiente onde foi submerso por conta da implantação da barragem. No Módulo Salto Simão, ambiente em que está situado o Sítio Arqueológico Piracanjuba, mostra a situação dos sítios arqueológicos no relevo, antes da implantação da barragem e após ação antrópica no ambiente. 
Figura 3 - Cenários da paisagem do Arqueológico Piracanjuba (Contexto ambiental - Ano de 1972 e 2018).

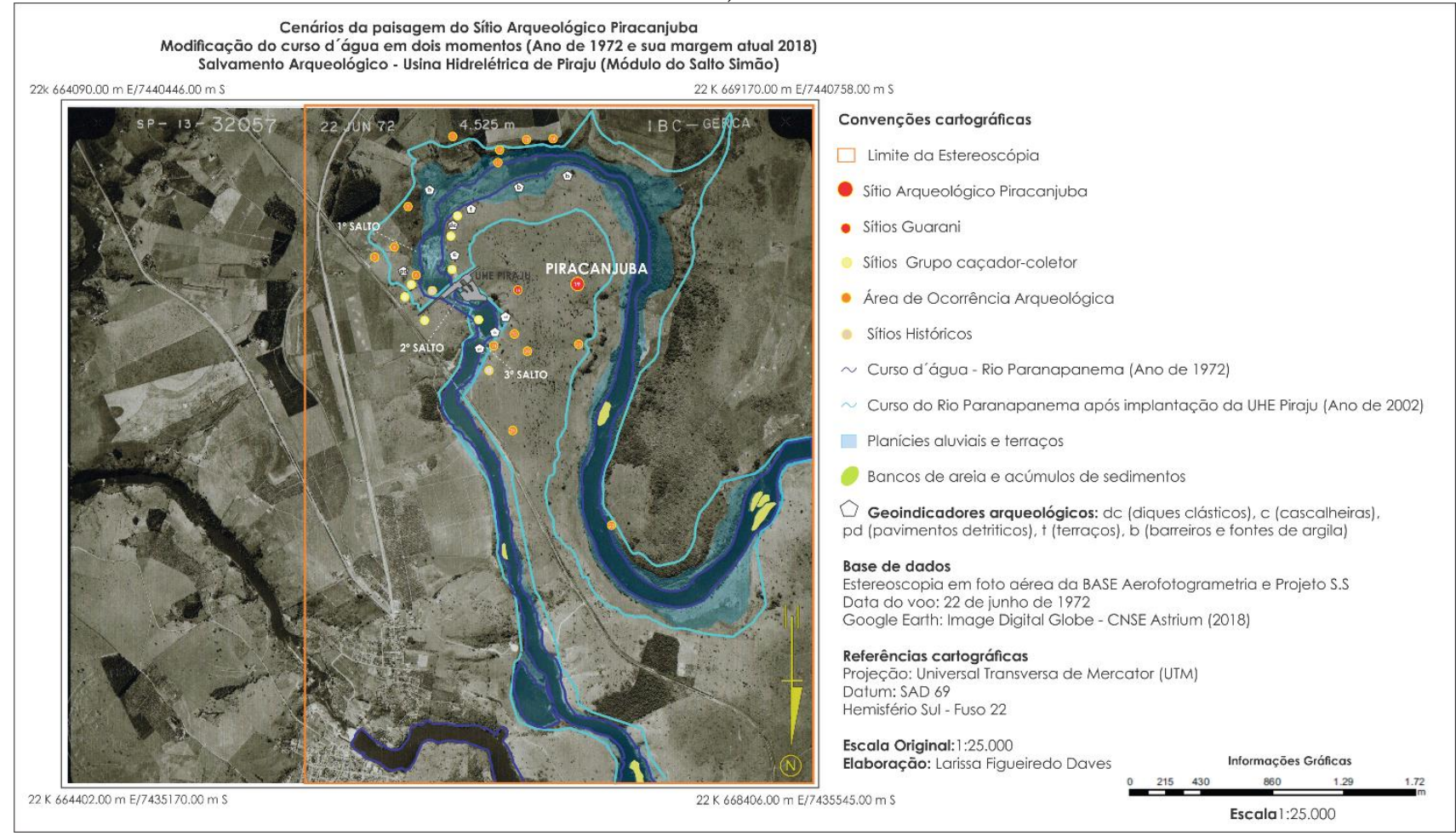

Fonte: Daves (2018).

\section{O Geofáceis: padrão de assentamento Guarani}

Do século XVII até meados do século XIX, as terras do Paranapanema ficaram praticamente despovoadas, com pequenos grupos de índios guarani, kaingang e xavante (MORAIS, 2010). A região do Rio Paranapanema foi colonizada por grupos de migrantes de Minas Gerais e da Região Nordeste do país, entre o final do século XIX e início do século XX; o cultivo do café e cultura agrícola consolidada em outras regiões do Estado de São Paulo expandiu para o Oeste do Estado, o que resultou na extraordinária procura de "terra" por parte dos fazendeiros (ABREU, 1972).

Esse processo de ocupação, conforme Abreu (1972), Monbeig (1984) e Leite (1999), decorreu de um intenso processo de degradação ambiental e do solo, a partir do desmatamento, seguido do extermínio das populações tradicionais indígenas e caboclas.

A ocupação na área onde se encontra o Sítio Arqueológico Piracanjuba, teve diferentes usos; em um primeiro momento foi ocupada pelo grupo guarani, e um segundo momento por cafezais e pastagem e, finalmente a implantação da UHE Piraju.

As aldeias de populações ceramistas Guarani mostram, de modo geral, a ocupação em área de meia-encosta de suaves relevos colinares. Nas áreas do Médio e Alto Paranapanema, os Guarani ocuparam espaços de meia encosta de vertentes suaves e áreas de topo de colina. No contexto do baixo Paranapanema, os Guarani ocuparam terraços, localizados em meia encosta de vertentes suaves e áreas de meia encosta, com a presença de um rio próximo ao local, quando distantes do Rio Paranapanema (FACCIO, 2011).

Faccio (2011) relata que o sistema de povoamento tem estado sempre estreitamente ligado às características da paisagem e seus componentes, pois os grupos humanos do passado escolhiam as localidades para ocupar guiados por parâmetros como a acessibilidade aos recursos naturais. No caso do Sítio Arqueológico Piracanjuba, indica característica comum ao padrão de assentamento dos sítios arqueológicos Guarani na área do Médio Paranapanema. Apresenta ocupação no relevo colinoso de vertentes côncavas e convexas, encaixado pelo canal de alta sinuosidade do Rio Paranapanema, indicando a possibilidade de maior visibilidade e acesso em relação ao seu entorno e proximidade ao curso d'água pelo grupo guarani.

A maioria dos Sítios Guarani ocupou relevo de meia encosta na Bacia do Rio Paranapanema. Esse atributo caracteriza o ambiente dos grupos 
ceramistas. Tal intepretação denota a inserção geral dos sítios na paisagem, influenciados pela morfologia do relevo e as características físicogeográficas (MORAIS, 1986).

A característica do padrão de assentamento e análise do ambiente permite levantar a hipótese de que o grupo Guarani que habitou o local desenvolvia o manejo de agricultura, pelo fato de ali se encontrar grande concentração de fragmentos cerâmicos com formas e tamanhos característicos para o cozimento (NOELLI, 1993).

De acordo com o Sistema Regional de Ocupação Guarani, o formato da aldeia com núcleos de solo antropogênico é indicativo de remanescente da tapy iguassu (a casa grande). Essas casas conhecidas como cabana grande são caracterizadas, em sua planta baixa, com forma alongada elipsoidal e alongada retangular de extremidades arredondadas, com base quadrangular e cobertura de sapé até o chão, constituindo uma construção sólida e resistente (NOELLI, 1993).

Noelli (1993) relata que o padrão característico da estrutura de habitação Guarani apresenta a forma alongada. A planta baixa arredondada da estrutura de habitação do grupo guarani, também denominada de ogapua "casa redonda" é representada em duas formas: alongada elipsoidal ou alongada composta com lado retangular e extremidades arredondadas. Essa forma arredondada ovalada elipsoidal das "manchas pretas" na superfície dos solos revolvidos dos sítios, parece ser resultante do tipo de colapso da casa (NOELLI, 1993).

\section{O Geótopo do Sítio Arqueológico Piracanjuba}

No período de escavação arqueológica no assentamento denominado Piracanjuba, foram coletados 15.288 fragmentos cerâmicos em quatro fundos de habitações e entornos (MORAIS, et.al. 2002). Apresentamos, a seguir a análise dos núcleos de solos antropogênicos que formam os geótopos de acordo com a unidade da paisagem e com o geossistema.

$\mathrm{Na}$ área dos núcleos de solo antropogênico do Sítio Piracanjuba (NSA 1, NSA 2, NSA 3 e NSA 4) foram encontrados vestígios de combustão pouco estruturados, ao redor dos quais se concentrou a maior parte da cerâmica (PANACHUK et. al., 2010).

Cada NSA apresenta diâmetro e extensão distinta em forma de elipse como nos demais sítios arqueológicos guarani estudados no Alto, Médio e Baixo Paranapanema (PALESTRINI, 1975; MORAIS, 2000; FACCIO, 2011). Tais manchas pretas são casas caídas de antigas habitações guarani. A distribuição dos fragmentos cerâmicos no perímetro do sítio arqueológico é organizada em duas hierarquias. $\mathrm{Na}$ área norte (NSA 2 e 4) apresentam-se dispersos. Na área sul (NSA 1 e 3), encontramse de forma compactada, apenas no NSA 1 (Figura 4).

Os núcleos de solo antropogênico do Sítio Arqueologico Piracanjuba apresentam $50 \mathrm{~cm}$ de profundidade com presença de matéria orgânica e vestígios arqueológicos. As dimensões do cinturão envoltório de cada NSA são distintos em formato elipsoide ovalada e/ou alongada (NSA 1- $20 \mathrm{~m}$ de comprimento, $10 \mathrm{~m}$ de largura; NSA $2-15 \mathrm{~m}$ de comprimento, $11 \mathrm{~m}$ de largura; NSA 3-12 metros de comprimento, $8 \mathrm{~m}$ de largura; NSA 4-10 m de comprimento, $8 \mathrm{~m}$ de largura).

A localização do Sítio Arqueológico Piracanjuba, na proximidade com o Rio Paranapanema mostra que o NSA 4 ocupa a posição mais alta da área do sítio $(571 \mathrm{~m})$, seguida, respectivamente, da NSA1, NSA2 e NSA3 $(570,569,567 \mathrm{~m})$. Verifica-se que na área norte do sítio arqueológico está a maior concentração de vestígios arqueológicos fora das NSAs, e que o sítio possui uma altitude de 567 a 571 metros. 
de fogueira com restos alimentares e potes quebrados.

A datação dos fragmentos cerâmicos no NSA 1, realizada em 2000, e a do NSA2, em 2004, apontam para os anos de 1520 d.C. e 1355 d.C., respectivamente, haja vista a disparidade das datações dos fragmentos cerâmicos [que] apontaram a expansão e o superdimensionamento da população na área do assentamento Guarani. (NOELLI, 1993). Também foram evidenciados no NSA 1 , restos faunísticos, restringidos a pequenos fragmentos ósseos queimados e um dente canino de macaco, seccionado e queimado.

O Geohorizonte enquanto subsidio para a análise vertical do Sítio Arqueológico Piracanjuba: perspectivas sobre relevo, clima, vegetação e solo

O Geohorizonte seria um estrato da paisagem onde houvesse a mesma combinação de geomassa, isto é, a diferenciação não estaria relacionada apenas à sequência de estratos vegetais e dos horizontes do solo, pois também deveria incluir as condições da hidrosfera e atmosfera (BEROUTCHACHVILI, 1989). No entanto o termo é essencial para a análise da estrutura vertical. Neste trabalho, sua utilização é associada aos componentes da paisagem e ao geocomplexo do sítio arqueológico.

A compreensão da escolha da posição geográfica do sítio arqueológico oferece elementos auxiliares para análise de evidências de coluvionamentos posteriores, pelos caracteres físico-químicos dos depósitos correlativos. Desse modo, a análise da estrutura superficial permite que o arqueólogo consiga comprovar os estudos cronogeomorfológicos a partir da datação dos vestígios arqueológicos e dos geoindicadores (tais como cascalheiras, diques basálticos, fontes de argila e afloramentos rochosos) com indícios de habitação em tempos pretéritos (CASSETI, 1983).

A localização de sítios arqueológicos préhistóricos apresenta um dinamismo diferente, dependendo de sua posição no relevo. Em vertente côncavo-convexa, a ruptura do declive resulta em um patamar onde pode estar localizado o sítio arqueológico pré-histórico. A análise da vertente deve estar subdividida em três escalas: inferior, média e superior (RUBIN, 2011).

Desse modo, a compartimentação topográfica é evidenciada como um referencial indispensável para a caracterização da área do sítio arqueológico, pois a análise da estrutura superficial procura observar o solo e os depósitos de cobertura vegetal presentes nas vertentes (CASSETI, 1983).

No caso do Sítio Arqueológico Piracanjuba, a vertente côncava foi analisada a partir de três unidades taxonômicas da paisagem: topo de colina/alta vertente, média vertente, baixa vertente. Conforme sua inclinação e declividade diminui em direção ao Rio Paranapanema, temos a média e baixa vertente. A dinâmica da vertente permitiu representar o estrato de vegetação em três ambientes distintos com base na discussão retratada por Beroutchachvilli e Bertrand (1978).

A metodologia utilizada na análise dos estratos de vegetação teve embasamento na análise fitossociológica proposta por BraunBlanquet (1979) e de Bertrand (1966). Inicialmente, realizamos o levantamento de espécies vegetais e observação do ambiente estudado. Após definir a área para o estudo da caracterização biogeográfica, foram relacionadas as espécies vegetais mais importantes, presentes na formação, segundo seu estrato, com ênfase para a descrição de cada ambiente do sítio arqueológico.

A classificação da vegetação teve como base a obra "Manual de Classificação da Vegetação Brasileira, adaptada a um sistema universal" segundo Veloso, Filho e Lima (1991). Além da discussão de Eiten (1983), Odum (1988), Troppmair (2012), Figueiró (2015) a respeito das espécies de vegetação presente na área do Sítio Arqueológico Piracanjuba.

Durante o trabalho de campo, no mês de abril de 2017, foram observadas características geográficas da área para detalhar os fatores biogeográficos que interferem na referida formação vegetal, buscando, também, os fatores de potencial ecológico que intervêm na paisagem.

O aspecto físico do Sítio Arqueológico Piracanjuba, apresenta o macro relevo formado pela Depressão Periférica Paulista (Depressão do Paranapanema) e morfoescultura do Planalto Ocidental Paulista (Planalto Centro Ocidental e Planalto Residual de Botucatu). O meso relevo caracterizado por colinas amplas de relevo colinoso. A delimitação do micro relevo tem como representação a vertente convexa (alta, média e baixa) de formação geológica da Serra Geral. O tipo de solo presente na vertente é formado por latossolo vermelho de caráter férrico, desenvolvidos de rochas basálticas. Além da concentração dos núcleos de solo antropogênico (FÚLFARO; SUGUIO, 1974).

A posição geográfica do Sítio Piracanjuba revela que sua população ocupou a área de topo e média da colina. Desse modo, a caracterização 
da vegetação e dos aspectos físicos teve enfoque na diversidade da cobertura vegetal em quatro setores da colina, sendo o topo da vertente, alta, média e baixa.

O Geohorizonte do Sítio Arqueológico Piracanjuba é formado por três unidades (alta, média e baixa vertente) distintas de estratificação heterogênea, contendo algumas espécies de vegetação semelhantes que se repetem na alta e baixa vertente. A distinção de cada ambiente é perceptível pela altura e característica da vegetação, além do declínio da vertente em direção ao corpo d'água do Rio Paranapanema (Figura 5).

Figura 5 - Geohorizonte do Sítio Arqueológico Piracanjuba, Piraju-SP.

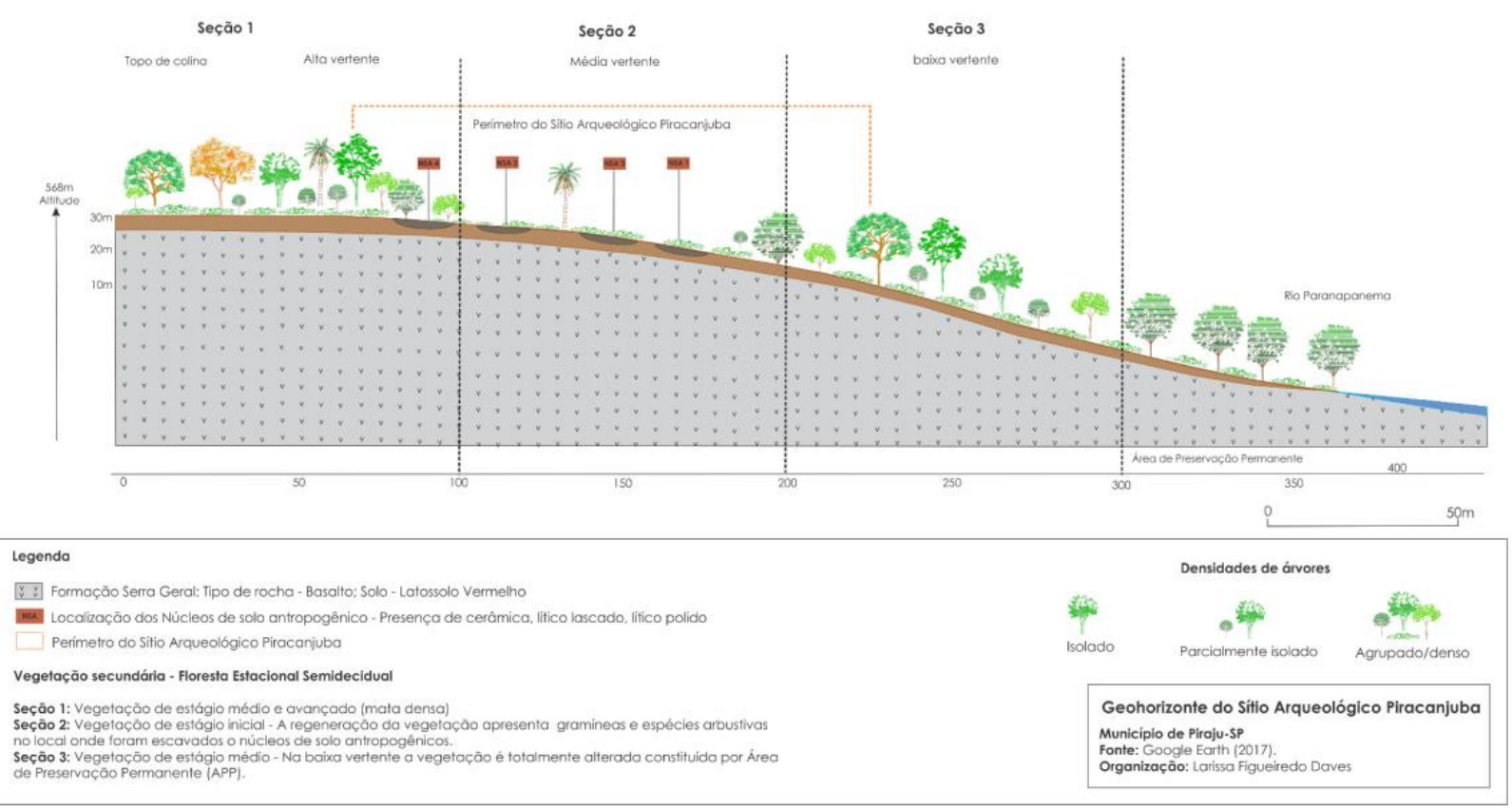

Fonte: Daves (2018).

A distinção de cada ambiente é perceptível pela altura de cada estrato de vegetação, além da declividade em direção ao corpo d'água do Rio Paranapanema. No topo da vertente a vegetação apresenta as espécies Canjerana (Cabralea canjerana), Cambuci (Campomanesia phaea), Jatobá (Hymenaea courbaril), Embaúba (Cecropia pachystachya), Palmeira Macaúba (Acrocomia aculeata), Paineira (Chorisia speciosa), Jequitibá (Cariniana estrellensis), Cedro (Cedrella fissilis), Canela Amarela (Nectandra oppositifolia) (Seção 1).

As espécies arbóreas formadas por Palmeira Macaúba (Acrocomia aculeata), Paineira (Chorisia speciosa), Picão Preto (Bidens alba), Carrapicho (Desmodium triflorum), Canela Amarela (Nectandra oppositifolia) dominam essa região (Seção 2).

$\mathrm{Na}$ proximidade com o corpo d'água, a característica está subordinada ao ambiente úmido, com presença de depósitos e sedimentos, principalmente pela concentração de sedimentos arenosos ao entorno do canal fluvial.
A vegetação da paisagem atual é composta de espécies dominantes de angiospermas e gramíneas com plantas de portes variados e indivíduos isolados. $\mathrm{Na}$ parte inferior da vertente, formou-se a mata ciliar, em processo de regeneração.

$\mathrm{O}$ estrato de vegetação é formado por gramínea e porte arbustivo (5 $\mathrm{cm}$ a 1 metro), composto por Picão Preto (Bidens alba), Carrapicho (Desmodium triflorum), Aroeira Vermelha (Schinus terebinthifolius), Goiabeira (Psidium guajava L.), Assa Peixe (Vernonia polysphaer) e Joá (Ziziphus joazeiro).

Na porção sul do sítio arqueológico, verificase o limite com o Rio Paranapanema, apresentando a vegetação secundária sem resquícios de vegetação nativa. Entre as espécies na porção inferior da vertente, destacam-se Embaúba (Cecropia pachystachya), Farinha Seca (Albiziahaslerii), Ingá (Ingaedulis), Ipê Amarelo (Tabebuia chrysotricha), Araribá (Centrolobium robustus), Angico Jacaré (Piptadenia gonoacantha), 
Jenipapo (Genipa americana), Canjerana (Cabralea canjerana) (Seção 3).

Segundo a Resolução do Conama n ${ }^{\circ}$ 1/1994, as espécies em estado de regeneração vegetação primária e secundária nos estágios pioneiro, inicial e avançado - no "bioma Mata Atlântica, neste caso, Floresta Estacional Semidecidual mostra os tipos de espécies nativa no Estado de São Paulo e quais característica em escala local ocorre a regeneração da vegetação" (CONAMA, 1994, p. 1684). Diante disso, são apresentadas a característica de estágio inicial e médio de vegetação secundária em processo de regeneração presentes no Sítio Arqueológico Piracanjuba.

O estágio inicial está presente na área de média vertente do Sítio Arqueológico Piracanjuba. A regeneração da vegetação apresenta diversidade biológica baixa, com espécies gramíneas e arbustivas dominantes na área em estágio pioneiro inicial. Neste ambiente a diversidade biológica é baixa, nota-se o destaque da regeneração de gramíneas presentes em todo local, principalmente na área onde foi escavado os NSAs. Em estágio médio de regeneração temos o ambiente da alta vertente e baixa vertente. No caso da alta vertente as espécies apresentam fisionomia florestal, apresentando árvores de vários tamanhos, além da presença de camadas de diferentes alturas, sendo que cada camada apresenta-se com cobertura variando de aberta a fechada. A superfície da camada superior é uniforme com árvores emergentes. A distribuição diamétrica do tronco das mesmas apresenta amplitude moderada com predomínio de pequenos diâmetros podendo gerar razoável produto lenhoso.

No topo de colina a mata fechada se estende até a alta vertente com característica de vegetação secundária de estagio médio, pois se encontra avançado comparado aos outros dois ambientes analisados no Sítio Arqueológico Piracanjuba. Tal aspecto é pelo fato de ter sofrido menos impacto neste ambiente. Nas árvores de porte médio e alto, onde a mata encontra-se fechada temos a ocorrência de trepadeiras e cipós. Também nota-se a presença de serapilheira formando uma camada sob o solo com espessura $5 \mathrm{~cm}$.

$\mathrm{Na}$ baixa vertente a vegetação é totalmente alterada. Conforme, o percentual de declividade ao longo da vertente nota-se a característica de vegetação secundária em diferentes estágios, formando estratos de sub-bosque e dossel de árvores com porte arbóreo (4 a 6 metros), nas extremidades, enquanto no interior predominavam gramíneas e árvores arbustivas isoladas (2 a 4 metros). Após o contexto alterado pela ação antrópica, a modificação do ecossistema permite observar algumas espécies de árvores nativas, presente no topo de colina e alta vertente e na Área de Preservação Permanente. Nas proximidades com o Rio Paranapanema o ambiente é úmido encharcado de vegetação ripária.

\section{CONCLUSÕES}

A característica do padrão de assentamento e análise do ambiente permite levantar a hipótese de que o grupo Guarani que habitou o local desenvolvia o manejo de agricultura, pelo fato de ali se encontrar grande concentração de fragmentos cerâmicos com formas e tamanhos característicos para o cozimento.

No perímetro do sítio arqueológico, porção de média vertente, pode-se dizer que se localizava a casa grande (tapy iguassu), como afirma a análise dos núcleos de solo antropogênico (geótopos). $\quad \mathrm{O}$ formato elipsóide e a característica dos núcleos de solo antropogênico correspondem a antigas habitações.

As análises dos núcleos de solo antropogênico revelaram a disparidade da datação por termoluminescência de fragmentos cerâmicos presentes no Núcleo de Solo Antropogênico 1 (NSA1) de 1520 d.C. e do Núcleo de Solo Antropogênico 2 (NSA 2) de 1355 d.C. apontando, provavelmente, para dois períodos de ocupação da área do sítio arqueológico.

$\mathrm{O}$ presente trabalho analisou as unidades de estratificação heterogênea a distinção de cada ambiente, perceptível pela altura de cada estrato de vegetação, além da sinuosidade e declividade da vertente, em direção ao corpo d'água do Rio Paranapanema. Contribuindo assim para estudos a respeito da análise da paisagem de sítios arqueológicos, em relação ao tempo pretérito com base nos geoindicadores. Diante disso, nota-se a relevância do estudo da paisagem sob a perspectiva da escala-temporal, pois devemos analisá-la de maneira abrangente, observando o processo pelo qual o local em foco se apresentava até o seu contexto atual.

\section{AGRADECIMENTOS}

Ao Laboratório de Arqueologia Guarani e Estudos da Paisagem (LAG) e ao Museu de Arqueologia Regional José Luiz de Morais (MAR) - FCT/ UNESP, Campus de Presidente 
Prudente. Ao CNPq (Conselho Nacional de Desenvolvimento Científico e Tecnológico).

\section{REFERÊNCIAS}

ABREU, D. S. Formação histórica de uma cidade pioneira paulista: Presidente Prudente. Presidente Prudente: FFCLPP, 1972.

ANSCHUETZ, K.F.; WILSHUEN, R. H.; SCHEIK, C.L. An Archaeology of Landscapes: Perspectives and Directions. Journal of Archaeological Research, Vol. 9, No. 2, 2001. https://doi.org/10.1023/A:1016621326415

ASHMORE, W.; KNAPP, A.B. Archaeologies of Landscape. Contemporene persperctives. 1999.

BEROUTCHACHVILI, N. L. Etologia da Paisagem e Cartografia dos Estados do Meio Natural. Tbilisi: Editora da Universidade de Tbilisi. 1989. 196p. (em russo).

BEROUTCHACHVILI, N. L.; BERTRAND, G. Le Géosystème ou Système territorial naturel. Revue Géographique des Pyrénés et du sudouest. Toulose. 1978. p. 167-180. https://doi.org/10.3406/rgpso.1978.3548

BEROUTCHACHVILI, N.L.; BERTRAND, G.. Le Géosystème ou Système territorial naturel. Revue Géographique des Pyrénés et du sudouest. Toulose. 1978. p. 167-180. https://doi.org/10.3406/rgpso.1978.3548

BERTRAND, G. Paisagem e Geografia Física global: um esboço metodológico. Caderno de Ciências da Terra. n.13. São Paulo. IGUSP. 1972. 27p.

BERTRAND, G."Pour une étude géographique de la végétation". R.G.P.S-O, t. XXXVII, TOULOUSE, 1966.

BERTRAND, G. Paysage et géographie physique globale: esquisse méthodologique. Revue géographique des Pyrénées et sud-ouest, v. 39 , fasc. $3, \quad 1968$. p. 249-272. https://doi.org/10.3406/rgpso.1968.4553

BERTRAND, G; BERTRAND, C. Uma Geografia Transversal e de Travessias: $o$ meio ambiente através dos territórios e das temporalidades. Maringá, PR: Editora Massoni, 2009.

BOADO, F. C. Construcción social del espacio y reconstrucción arqueológica del paisaje. Boletín de Antropología Americana, 24, p. 5-29, 1991. BOADO, F. C. Del Terreno al Espacio: planteamientos y perspectivas para la arqueología del paisaje. CAPA 6: critérios y convenciones em arqueologia del paisaje, Santiago de Compostela, 1999.

BOADO, F. C. Límites y posibilidades de la Arqueología del paisaje. SPAL, Revista de Prehistoria y Arqueología, Sevilla, p. 9-55., 1993.
BRAUN BLANQUET, J. Fitossociologia: bases para el estudio de las comunidades vegetales. Madrid: Blume, 1979.

CASSETI, V. A natureza e o espaço geográfico. In: MENDONÇA, F. A.; KOZEL, S. (Org.). Elementos de Epistemologia da Geografia Contemporânea. Curitiba, PR: Editora UFPR, p. 145-163, 2009.

CASSETI, V. Elementos da Geomorfologia aplicados à Arqueologia. Revista do ICHLUniversidade Federal de Goiás, ano 1, nº 1, 1983.

CASSETI, V. Elementos de geomorfologia.

Goiânia: Editora da UFG, 2001.

CONAMA. RESOLUÇÃO $\mathbf{n}^{\mathbf{0}} \mathbf{1}$, de 31 de janeiro de 1994. Publicada no DOU no 24 , de 3 de fevereiro de 1994, Seção 1, páginas 1684-1685.

DAVES, L. F. O estudo do sítio arqueológico Piracanjuba sob enfoque da Arqueologia da Paisagem. Dissertação de Mestrado, FCTUNESP, Campus de Presidente Prudente, p.177, 2018.

EITEN, G. Classificação da vegetação do Brasil. Brasília, DF: Conselho Nacional de Desenvolvimento Científico e Tecnológico $\mathrm{CNPq}, 1983.305 \mathrm{p}$.

FACCIO, N. B. Arqueologia Guarani na Área do Projeto Paranapanema: estudo dos sítios de Iepê, SP. Volume I. Tese de Livre Docência Museu de Arqueologia e Etnografia, Programa de Pós-Graduação em Arqueologia - Universidade de São Paulo, São Paulo, 2011.

FIGUEIRÓ, A. Biogeografia: dinâmicas e transformação da natureza. Oficina de Textos. Organização Francisco Mendonça. 2015, p. 52.

FRANCO, C. Visão sistêmica do Sítio Arqueológico Piracanjuba: a descoberta de conhecimento em sítios arqueológicos. Tese de Doutorado, UNESP/FCT- Campus de Presidente Prudente, Presidente Prudente, 2007, p. 14.

FÚLFARO; V.J. SUGUIO, K. Geologia da região de Fartura. In: Congresso Brasileiro de Geologia, 28, Porto Alegre, SBG, v.4, p. 173-180, 1974.

GOOGLE. Google Earth Pro. Website .Image Satélite Digital Globe. CNSE Astrium/, 2017 e 2018.

HOLLENBACK, K. L. Landscapes. In: SCHIFFER, M. B. Behavioral Archaeology. Equinox, Londres: 2010. p.186-193.

IBGE. Instituto Brasileiro de Geografia e Estatística. Malhas digitais - Bases cartográficas do Município de Piraju-SP. Ano de 2016.

KORMIKIARI, C. N. Arqueologia da Paisagem. Revista eletrônica ResearchGate. Disponível em:

https://www.researchgate.net/publication/27766 5375_ARQUEOLOGIA_DA_PAISAGEM，2000, p. 1-20.

LEITE, J, F. A ocupação do Pontal do Paranapanema. Tese de Livre Docência. 
Instituto de Planejamento e Estudos Ambientais da Universidade Estadual Paulista - Campus de Presidente Prudente, p.256, 1983.

MONTEIRO, C.A. F. A dinâmica climática e as chuvas do Estado de São Paulo: estudo geográfico sob forma de atlas. São Paulo: IGEOG, 1973.

MONBEIG, P. Pioneiros e fazendeiros de São Paulo. Tradução Ary França e Raul de Andrade e Silva. São Paulo: Hucitec/Polis, 1984.

MORAIS, J. L. Arqueologia da Região Sudeste. Revista da USP, $\mathrm{n}^{\circ} 44,194-217,1999$.

MORAIS, J. L. A Propósito da Interdisciplinaridade em Arqueologia. Revista do Museu Paulista, Editora da Universidade de São Paulo, São Paulo, v. XXXII, p. 155, 1986.

MORAIS, J. L.; FACCIO, N.B.; PIEDADE, S. C.M. Salvamento arqueológico da UHE PIRAJU ARQPIRAJU. Relatório técnico de Arqueologia preventiva, vol. 1, 2 e 3 . São Paulo. Ano 2000, 2002 e 2003.

NOELLI, F. S. Sem Tekoha não há Tekó: em busca de um Modelo Etnoarqueológico da Aldeia e da Subsistência Guarani e sua aplicação a uma área de domínio no Delta do Jacuí - RS. Porto Alegre. Dissertação de Mestrado PUC-RS, 1993.

ODUM, E, P. Ecologia. 1913. Tradução: Ricardo Iglesias Rios; Christopher J. Tribe. Rio de Janeiro: Guanabara Koogan, 2010.

PALLESTRINI, L. Interpretações de estruturas arqueológicas em sítios do Estado de São Paulo, São Paulo: Museu Paulista. (Coleção Museu Paulista, Série Arqueologia), 1975.

PANACHUK, L.; CARVALHO, A.; JÁCOME, C. et. al. Reflexões sobre as aldeias Tupiguarani: apontamentos metodológicos. In: PROUS, A.; LIMA, T. A. (Orgs.). Os ceramistas Tupiguarani: eixos temáticos. Belo Horizonte: IPHAN, v. 3, 2010.

PASSOS, M. M. A Raia Divisória: geossistema, paisagem e eco-história. Maringá: Eduem, 2006.

PASSOS, M. M. Biogeografia e Paisagem. $2^{\mathrm{a}}$ ed. Presidente Prudente: UNESP - PPGE, $2^{\mathrm{a}}$. Edição, 2003.

ROSS, J.L.S. Registro cartográfico dos fatos geomorfológicos e a questão da taxonomia do relevo. Revista do Departamento de Geografia. 17-29 pp. São Paulo, IG-USP, 1991. https://doi.org/10.7154/RDG.1992.0006.0002
RUBIN, J.C.R; SILVA, R.T. Arqueologia, dinâmica das vertentes e perdas de solo. Rev. do Museu de Arqueologia e Etnologia, São Paulo, 14: 179-193, 2004. https://doi.org/10.11606/issn.2448-

1750.revmae.2004.89666

RUBIN, J.C.R; CARBONERA, M. Considerações acerca do contexto ambiental dos sítios arqueológicos do alto rio Uruguai: Projeto Salvamento Arqueológico Uruguai UHE-Itá. R. Museu Arq. Etn., São Paulo, n. 21, p. 153-166, 2011.

SUERTEGARAY, D. M. A. Geografia Física(?) geografia ambiental(?) ou geografia e ambiente (?). In: MENDONÇA, F. A.; KOZEL, S. (Org.). Elementos de Epistemologia da Geografia Contemporânea. Curitiba - PR: Editora UFPR, v. 2. p. 111-120, 2009.

TROPPMAIR, H. 1933. Biogeografia e meio ambiente. 9 ed - Rio de Janeiro: Technical Books, 2012.

VICENT, J. M. G. Fundamentos teóricometodológicos para um programa de investigação Arqueo-Geográfica. In: López Garcia (dir.): El cambio cultural del IV a II milênios a.C. en la comarca noroeste de Murcia, Madrid: Consejo Superior de Investigaciones Científicas, 1991, p.29-117.

VELOSO, H. P.; FILHO, A.L.R.R.; Classificação da vegetação brasileira, adaptada a um sistema universal. Rio de Janeiro IBGE, Departamento de Recursos Naturais e Estudos Ambientais, 1991.

WATERS, M. R. Principles of geoarchaeology. A North American perspective. Tucson: The University of Arizona Press, 1992.

\section{CONTRIBUIÇÃO DOS AUTORES}

Larissa Figueiredo Daves contribuiu com a Metodologia, Curadoria de dados, Forma de análise, Visualização, Escrita (rascunho original; revisão e edição). Neide Barrocá Faccio contribuiu com a Escrita (revisão), Metodologia, Recursos para análise dos materiais. 